\title{
The clinical course of idiopathic pulmonary fibrosis and its association to quality of life over time: longitudinal data from the INSIGHTS-IPF registry
}

Michael Kreuter ${ }^{1,26^{*}}$, Jeff Swigris², David Pittrow ${ }^{3}$, Silke Geier ${ }^{4}$, Jens Klotsche ${ }^{5}$, Antje Prasse ${ }^{6,7,26}$, Hubert Wirtz ${ }^{8}$, Dirk Koschel ${ }^{9}$, Stefan Andreas ${ }^{10}$, Martin Claussen ${ }^{11,26}$, Christian Grohé ${ }^{12}$, Henrike Wilkens ${ }^{13}$, Lars Hagmeyer ${ }^{14}$, Dirk Skowasch ${ }^{15}$, Joachim F. Meyer ${ }^{16}$, Joachim Kirschner ${ }^{17}$, Sven Gläser ${ }^{18,19}$, Nicolas Kahn ${ }^{1,26}$, Tobias Welte ${ }^{6,26}$, Claus Neurohr ${ }^{20,24}$, Martin Schwaiblmair ${ }^{21}$, Matthias Held ${ }^{22}$, Thomas Bahmer ${ }^{11,26}$, Tim Oqueka ${ }^{25}$, Marion Frankenberger $20,23,26$ and Jürgen Behr ${ }^{20,23,26}$

\begin{abstract}
Background: Quality of life (QoL) is profoundly impaired in patients with idiopathic pulmonary fibrosis (IPF). However, data is limited regarding the course of QoL. We therefore analysed longitudinal data from the German INSIGHTS-IPF registry.

Methods: Clinical status and QoL were assessed at enrollment and subsequently at 6- to 12-months intervals. A range of different QoL questionnaires including the St. George's Respiratory Questionnaire (SGRQ) were used.

Results: Data from 424 patients were included; 76.9\% male; mean age 68.7 \pm 9.1 years, mean FVC\% predicted $75.9 \pm 19.4$, mean $\mathrm{DL}_{\mathrm{CO}} \%$ predicted 36.1 \pm 15.9. QoL worsened significantly during follow-up with higher total SGRQ scores (increased by 1.47 per year; $95 \% \mathrm{Cl}: 1.17$ to $1.76 ; p<0.001$ ) and higher UCSD-SOBQ scores and lower EQ-5D VAS and WHO- 5 scores. An absolute decline in FVC\% predicted of $>10 \%$ was associated with a significant deterioration in SGRQ (increasing by 9.08 units; $95 \% \mathrm{Cl}: 2.48$ to 15.67; $p=0.007$ ), while patients with stable or improved FVC had no significantly change in SGRQ. Patients with a $>10 \%$ decrease of $D_{C O} \%$ predicted also had a significant increase in SGRQ (+ 7.79 units; 95\% Cl: 0.85 to $14.73 ; p=0.028$ ), while SQRQ was almost stable in patients with stable or improved DLco. Patients who died had a significant greater increase in SGRQ total scores (mean 11.8 \pm 18.6 ) at their last follow-up visit prior to death compared to survivors (mean 4.2 \pm 18.9; $\mathrm{HR}=1.03 ; 95 \% \mathrm{Cl}$ : 1.01 to 1.04; $p<0.001$ ). All QoL scores across the follow-up period were significantly worse in hospitalised patients compared to non-hospitalised patients, with the worst scores reported in those hospitalised for acute exacerbations.
\end{abstract}

Conclusions: QoL assessments in the INSIGHTS-IPF registry demonstrate a close relationship between QoL and clinically meaningful changes in lung function, comorbidities, disease duration and clinical course of IPF, including hospitalisation and mortality.

Keywords: Idiopathic pulmonary fibrosis, Patient-related outcomes, Cohort study, SQRQ

\footnotetext{
* Correspondence: kreuter@uni-heidelberg.de

${ }^{1}$ Center for interstitial and rare lung diseases, Thoraxklinik, University of

Heidelberg, Röntgenstr 1, D-69126 Heidelberg, Germany

${ }^{26}$ German Center for Lung Research, gießen, Germany

Full list of author information is available at the end of the article
}

(c) The Author(s). 2019 Open Access This article is distributed under the terms of the Creative Commons Attribution 4.0 International License (http://creativecommons.org/licenses/by/4.0/), which permits unrestricted use, distribution, and reproduction in any medium, provided you give appropriate credit to the original author(s) and the source, provide a link to the Creative Commons license, and indicate if changes were made. The Creative Commons Public Domain Dedication waiver (http://creativecommons.org/publicdomain/zero/1.0/) applies to the data made available in this article, unless otherwise stated. 


\section{Introduction}

Idiopathic pulmonary fibrosis (IPF) is a severe disease characterised by debilitating symptoms such as cough, fatigue, increasing and immobilising dyspnoea and is associated with a limited survival [1,2]. IPF symptoms and outcomes are also strongly influenced by co-morbidities $[3,4]$. The psychosocial impact of IPF is substantial for both patients and their caregivers [1,5]. Recent reports have shown that in IPF patients health-related quality of life (QoL) is associated with clinical symptoms, duration of disease, physical activity, comorbidities, and disease severity [6-10] and may be prognostic [11].

While current therapies aim to improve the disease course and to prolong life expectancy, less well understood is how best to improve an individual's health-related quality of life and psychosocial needs [12]. To address this, patient-reported outcomes incorporating determination of health-related quality of life (QoL) assessments are increasingly used as important outcome measures, in clinical practice and in clinical trials [6]. However, data on longitudinal determinations of QoL in IPF patients, especially in the real-life setting are sparse. Previously, we have reported on baseline characteristics and QoL status in patients enrolled in a large nationwide observational IPF registry (INSIGHTS-IPF) [2, 7]. In the present analyses, we report longitudinal data (with up to 36 months follow-up) for a range of QoL measures and examine changes in QoL outcomes and their relationship to clinical parameters.

\section{Methods}

\section{Study population}

The INSIGHTS-IPF ("Investigating significant health trends in idiopathic pulmonary fibrosis") registry is a nationwide, investigator-initiated cohort study, which has been continuously enrolling consecutive patients in routine clinical care across 19 pulmonary specialist centres in Germany since November 2012. Patients $\geq 18$ years of age with a study-site diagnosis of IPF after provision of written informed consent can be enrolled, with no explicit exclusion criteria. The registry's structure, methodology and regulatory aspects, and a detailed description of the baseline characteristics of the patient cohort have been reported [2, 13, 14]. Patients with a QoL assessment at baseline and at least one follow-up assessment were available for this study. The change in QoL was studied for 3 years after enrolment into the registry (i.e., 3 -year follow-up), because of the currently limited number of patients $(n=24)$ with available QoL data for follow-up beyond this time-point.

\section{Clinical and patient-reported outcome measures}

Data were collected at enrolment (baseline) and at subsequent 6- to 12 months intervals. At each follow-up visit, all clinical events including hospitalisation and acute exacerbations (as judged by the treating physician), and death were recorded by each site. At these visits, a range of routine pulmonary function tests were documented, including forced vital capacity (FVC) \% predicted, diffusing capacity of the lung for carbon monoxide $\left(\mathrm{DL}_{\mathrm{CO}}\right) \%$ predicted, the forced expiratory volume in $1 \mathrm{~s}\left(\mathrm{FEV}_{1}\right)$, and six-minute walk distance (6MWD). The Gender, Age, Physiology (GAP) index was also determined. All patients completed the NYHA functional status and a range of QoL questionnaires as previously reported [7]. These include the St. George's Respiratory Questionnaire (SGRQ), the University of California San Diego Shortness of Breath Questionnaire (USCD-SOBQ), the EuroQol five-dimensional questionnaire, recorded as a visual analogue scale (EQ-VAS), and the World Health Organization-5 Well-Being Index (WHO-5). At each visit, where possible the treating physician made and recorded their judgement of overall disease course (stable disease, slow progression, rapid progression) according to Behr et al. (2). Functional changes were categorized as stable/increased if FVC did not change or was improved by $\geq 0 \%$, as a moderate decrease between $>0-10 \%$ and a significant decrease in case of $>10 \%$.

All data were collected using an internet-based case report form (eCRF) with secure electronic data transfer to the central database. Quality measures included automated plausibility checks at data entry, statistical checks on data quality (focussing on missing values and outliers) as well as on-site monitoring and source data verification performed in the majority of centres (over 70\%).

\section{Data analysis}

Data were summarised by descriptive statistics including means and standard deviations and absolute and relative frequencies at baseline and each subsequent follow-up assessment. Baseline characteristics were compared by t-test for continuously distributed variables and Chi2 test for categorical variables between patients who were included in the analyses and excluded by missing QoL assessments. Linear mixed models were applied to investigate the change in QoL in follow-up with the study centres as cluster variable. Clinical characteristics such as lung function test at baseline (time invariant) and follow-up (time varying) were used to analyse possible associations with the change in QoL across time by linear mixed models. The association of mortality with QoL at the last available follow-up and change in QoL between baseline and last follow-up was analysed by Cox proportional hazard models. Hospitalisations for any reason and hospitalisations due to exacerbation in follow-up were investigated by linear mixed models. Multivariable regression models for mortality and 
hospitalisations included lung function test, the number of comorbidities, age and the physicians global judgement about disease activity as covariates. A $p$-value of lower than 0.05 was considered to be statistically significant.

Data were analysed with STATA 12.1 (StataCorp LP. Stata Statistical Software: Release 12. College Station, TX, USA).

\section{Results}

\section{Patient characteristics}

Of 879 patients, a total of 424 patients provided QoL data at baseline and at least at one follow-up visit, and were included in these analyses. Baseline characteristics of this cohort are presented in Table 1. Baseline characteristics for patients who were not included due to missing follow-up assessment of QoL -in comparison to the cohort reported here- are presented in Additional file 1: Table S4. For this the cohort, the patients mean age was $68.7 \pm 9.1$ years, $76.9 \%$ were male, and mean symptom duration was $3.7 \pm 4.1$ years, with $61.3 \%$ having disease for more than 6 months at registry enrolment; $60.4 \%$ of participants were former smokers with $38.0 \%$ never having smoked. Most patients (77.6\%) had one or more comorbidities. At baseline, the IPF was judged by treating physicians as stable in $39.2 \%$ of patients, slowly progressing in $29.0 \%$ and rapidly progressing in $7.3 \%$. Most patients were in NYHA functional class II/III at enrolment, with a mean $6 \mathrm{MWD}$ of $288 \pm 200 \mathrm{~m}$. Mean values for respiratory parameters were; $\mathrm{FVC} \%$ predicted $(75.9 \% \pm 19.4), \mathrm{FEV}_{1} \%(68.3 \% \pm 17.4)$, and $\mathrm{DL}_{\mathrm{CO}} \%$ predicted $(36.1 \% \pm 15.9)$; $53.0 \%$ were in GAP index stage 2 and $28.2 \%$ in stage 3 .

At baseline the mean SGRQ total score was $45.9 \pm$ 19.7, with higher scores for the SGRQ activity domain $(59.7 \pm 23.6)$ than symptom or impact domains. Patient reported breathlessness with a mean USCD-SOBQ score of $43.9 \pm 28.8$. Mean EQ-5D VAS scores were $62.6 \pm 1$ 8.5 with mean WHO-5 scores of $14.8 \pm 5.7$.

\section{Change in QoL over time and associations to clinical parameters during follow up}

The courses for QoL scores from baseline to last follow-up visit are shown in Fig. 1 (and in online data supplement; Additional file 2: Table S1). Longitudinal data showed a significant increase in SGRQ total scores (beta $=1.47,95 \% \mathrm{CI}: 1.17$ to $1.76 ; p<0.001$ ) and UCSD-SOBQ score (beta $=3.63,95 \%$ CI: 3.07 to 4.18 ; $p<0.001)$ per half-year between baseline and 36-months follow-up (indicating poorer QoL compared to baseline). EQ-5D VAS scores and WHO-5 scores also significantly decreased across time indicating a worsening QoL (Additional file 2: Table S1).
Table 1 Sociodemographic and clinical parameters of the patient cohort analysed

\begin{tabular}{|c|c|}
\hline Patient characteristics & $\begin{array}{l}\mathrm{n}(\%) / \text { mean }(\mathrm{SD}) \\
n=424\end{array}$ \\
\hline Female & $98(23.1 \%)$ \\
\hline Age in years & $68.7(9.1)$ \\
\hline Age at first symptom onset in years & $64.9(10.3)$ \\
\hline Age at diagnosis in years & $66.8(9.7)$ \\
\hline Duration since first symptoms in years & $3.7(4.1)$ \\
\hline Disease duration in months & $2.0(2.7)$ \\
\hline$<3$ months & $124(29.5 \%)$ \\
\hline 3 to $<6$ months & $39(9.3 \%)$ \\
\hline More than 6 months & $258(61.3 \%)$ \\
\hline \multicolumn{2}{|l|}{ Smoking status } \\
\hline Never & $161(38.0 \%)$ \\
\hline Former stopped & $256(60.4 \%)$ \\
\hline Current & $7(1.7 \%)$ \\
\hline \multicolumn{2}{|l|}{ Number of comorbidities } \\
\hline None & $95(22.4 \%)$ \\
\hline 1 & $124(29.3 \%)$ \\
\hline 2 & $107(25.2 \%)$ \\
\hline 3 & $63(14.9 \%)$ \\
\hline $4+$ & $35(8.3 \%)$ \\
\hline \multicolumn{2}{|l|}{ NHYA } \\
\hline 1 & $28(14.7 \%)$ \\
\hline$\|$ & $81(42.6 \%)$ \\
\hline III & $76(40.0 \%)$ \\
\hline IV & $5(2.6 \%)$ \\
\hline Six-minute walk distance (m) & $287.7(199.6)$ \\
\hline$\% \mathrm{FEV}_{1}$ & $68.3(17.4)$ \\
\hline$\%$ FVC & $36.1(15.9)$ \\
\hline$\% \mathrm{DL}_{\mathrm{CO}}$ & $75.9(19.4)$ \\
\hline GAP index & $4.7(1.4)$ \\
\hline Stage I & $72(18.8 \%)$ \\
\hline Stage II & $203(53.0 \%)$ \\
\hline Stage III & $108(28.2 \%)$ \\
\hline \multicolumn{2}{|c|}{ Overall physician's judgement of clinical course of IPF } \\
\hline Stable disease & $166(39.2 \%)$ \\
\hline Slow progression & $123(29.0 \%)$ \\
\hline Rapid progression & $31(7.3 \%)$ \\
\hline No judgement possible & $104(24.5 \%)$ \\
\hline SGRQ & $45.9(19.7)$ \\
\hline SGRQ symptoms & $55.9(21.0)$ \\
\hline SGRQ activity & $59.7(23.6)$ \\
\hline
\end{tabular}


Table 1 Sociodemographic and clinical parameters of the patient cohort analysed (Continued)

\begin{tabular}{ll}
\hline Patient characteristics & $\begin{array}{l}\mathrm{n}(\%) / \text { mean (SD) } \\
n=424\end{array}$ \\
\hline SGRQ impacts & $34.8(20.7)$ \\
UCSD-SOBQ & $43.9(28.8)$ \\
EQ-5D VAS & $62.6(18.5)$ \\
WHO-5 & $14.8(5.7)$ \\
\hline
\end{tabular}

Values are $\mathrm{n}(\%)$ or mean (SD)

$D L_{C O}$ diffusing capacity of the lung for carbon monoxide, EQ-5D VAS EuroQol five-dimensional questionnaire, recorded as a visual analog scale, $F E V$, Forced expiratory volume in $1 \mathrm{~s}, F V C$ forced vital capacity, GAP index Gender, Age, Physiology index, IPF idiopathic pulmonary fibrosis, NYHA New York Heart Association functional class, SD standard deviation, SGRQ St. George's Respiratory Questionnaire, USCD-SOBQ University of California San Diego Shortness of Breath Questionnaire, WHO-5 World Health Organization-5 Well-Being Index

Details about the association between the different QoL measures and clinical characteristics at baseline and change in clinical parameters in follow-up are reported in Table 2. Female patients reported significant higher, i.e. poorer SGRQ scores during follow-up (beta = 5.42, 95\% CI: 1.13 to 9.71; $p=0.013$ ) compared to males. A higher NYHA stage, GAP index and a more severe assessment of the clinical course of the patient by the treating physician at baseline were associated with higher, i.e. worse SGRQ scores. The more impaired the lung function was at baseline, the higher were the SQRQ scores during follow-up. Patients with more than a $10 \%$ decrease of $\mathrm{FVC} \%$ predicted and/or $\mathrm{DL}_{\mathrm{CO}} \%$ predicted within 1 year reported significantly worse SQRQ scores during follow-up compared to stable patients; FVC \% predicted (beta $=9.08 ; 95 \% \mathrm{CI}: 2.48$ to $15.67 ; p=$ 0.007 ); $\mathrm{DL}_{\mathrm{CO}} \%$ predicted (beta $=7.79 ; 95 \% \mathrm{CI}: 0.85$ to $14.73 ; p=0.028)$. Comparable results were observed for the other QoL measures (Table 2).

SGRQ at last follow-up, and change in SGRQ between baseline and last follow-up in association to lung functional changes within 1 year are shown in Fig. 2. More complete data for the SGRQ and those for all other QoL measures are presented in the online data supplement (Additional file 2: Table S2). The deterioration in SGRQ scores until last follow-up was associated with a worsening of $\mathrm{FVC} \%$ predicted and $\mathrm{DL}_{\mathrm{CO}} \%$ predicted within 1 year after enrolment. In patients with stable or even improving, i.e. increasing FVC \% predicted, SGRQ scores after 36 months follow-up remained relatively unchanged from baseline (mean - 0.1 units $\neq 21.1$ ) with SGRQ at 36-months of 45.7 units ₹ SD 19.5. In contrast, compared to these patients, those patients with a decline of $>10 \%$ in FVC \% predicted reported a significantly higher increase in SQRQ scores from baseline (mean $20.6 \neq 19.1$, beta $=$ 20.71; 95\% CI: 13.09 to 28.33 ; $p<0.001$ ) and significantly higher SGRQ scores at last follow-up (mean $=64.1 \neq 19.6$, beta $=18.43$; $95 \%$ CI: 10.98 to 25.87 ). There was also a non-significant trend towards a worse SGRQ for patients with a moderate lung functional decline compared to

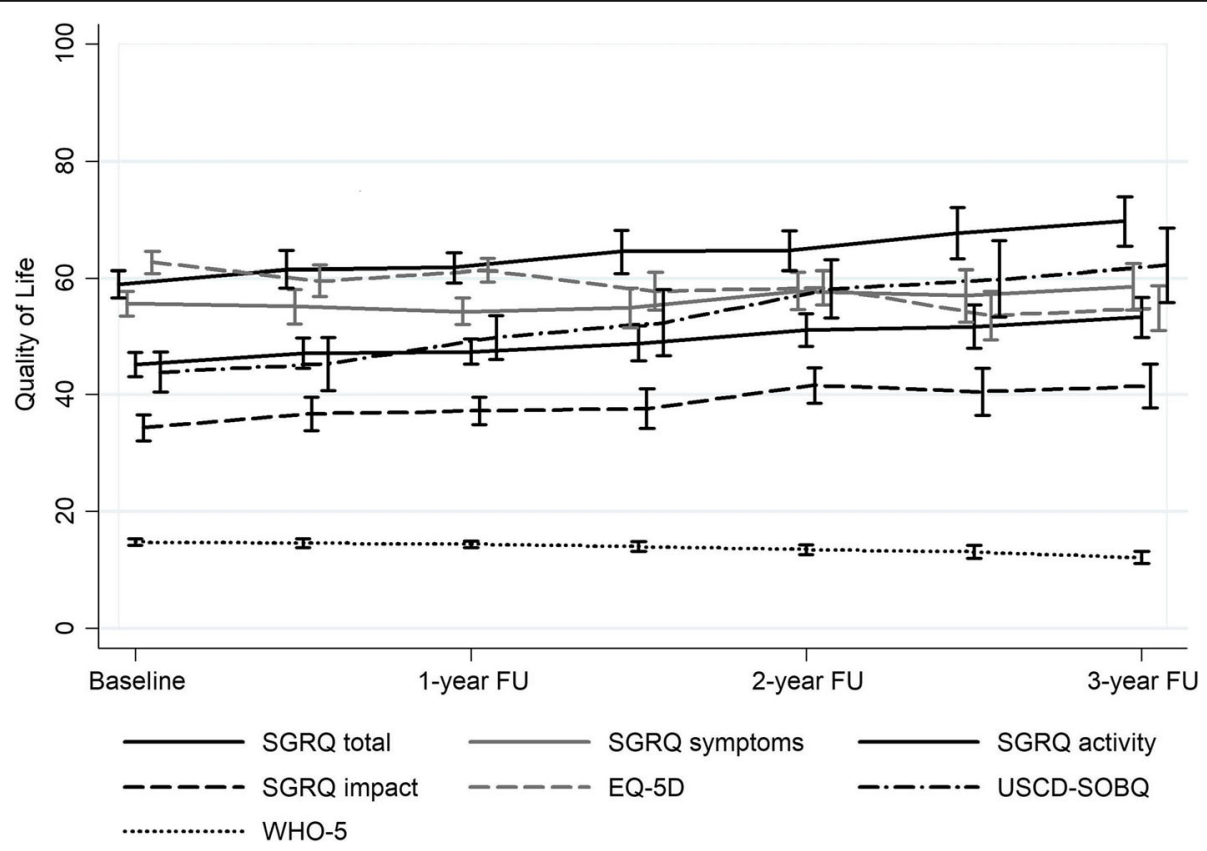

Fig. 1 Change in QoL over 3 years of follow-up SGRQ $(p<0.001)$, SGRQ symptoms ( $p=0.142)$, SGRQ activity $(p<0.001)$, SGRQ impacts $(p<0.001)$, EQ-5D VAS $(p<0.001)$, UCSD Shortness of breath $(p<0.001)$, WHO-5 $(p<0.001))$ over 3 years of follow-up. EQ-5D VAS, EuroQol five-dimensional questionnaire, recorded as a visual analog scale; QoL, quality of life; SGRQ, St. George's Respiratory Questionnaire; USCD-SOBQ, University of California San Diego Shortness of Breath Questionnaire; WHO-5, World Health Organization-5 Well-Being Index 
Table 2 Associations of QoL with clinical parameters at baseline and change in clinical parameters in follow-up

\begin{tabular}{|c|c|c|c|c|c|c|c|c|c|c|c|c|}
\hline & \multicolumn{3}{|c|}{ SGRQ total } & \multicolumn{3}{|c|}{ EQ 5D VAS } & \multicolumn{4}{|c|}{ UCSD-SOBQ } & \multicolumn{2}{|l|}{ WHO-5 } \\
\hline & beta & $95 \% \mathrm{Cl}$ & $p$-value & beta & $95 \% \mathrm{Cl}$ & $p$-value & beta & $95 \% \mathrm{Cl}$ & $p$-value & beta & $95 \% \mathrm{Cl}$ & $p$-value \\
\hline Female sex & 5.42 & $1.13 ; 9.71$ & 0.013 & -3.36 & $-6.90 ; 0.18$ & 0.063 & 13.56 & $6.41 ; 20.72$ & $<0.001$ & -1.47 & $-2.60 ;-0.33$ & 0.011 \\
\hline Age & 0.00 & $-0.19 ; 0.20$ & 0.963 & -0.18 & $-0.34 ;-0.02$ & 0.029 & 0.35 & $0.04 ; 0.66$ & 0.026 & -0.05 & $-0.10 ; 0.00$ & 0.074 \\
\hline $\begin{array}{l}\text { Age at first symptom } \\
\text { onset in years }\end{array}$ & -0.10 & $-0.28 ; 0.08$ & 0.285 & -0.08 & $-0.22 ; 0.07$ & 0.323 & 0.17 & $-0.11 ; 0.46$ & 0.238 & -0.03 & $-0.07 ; 0.02$ & 0.299 \\
\hline $\begin{array}{l}\text { Age at diagnosis in } \\
\text { years }\end{array}$ & -0.09 & $-0.28 ; 0.09$ & 0.320 & -0.08 & $-0.23 ; 0.07$ & 0.290 & 0.18 & $-0.11 ; 0.48$ & 0.227 & -0.02 & $-0.07 ; 0.03$ & 0.400 \\
\hline $\begin{array}{l}\text { Duration since first } \\
\text { symptoms in years }\end{array}$ & 0.73 & $0.28 ; 1.18$ & 0.002 & -0.51 & $-0.89 ;-0.13$ & 0.008 & 0.71 & $-0.04 ; 1.46$ & 0.062 & -0.09 & $-0.21 ; 0.03$ & 0.139 \\
\hline $\begin{array}{l}\text { Disease duration } \\
\text { in months }\end{array}$ & 1.36 & $0.70 ; 2.02$ & $<0.001$ & -1.10 & $-1.65 ;-0.55$ & $<0.001$ & 1.70 & $0.64 ; 2.77$ & 0.002 & -0.25 & $-0.43 ;-0.08$ & 0.005 \\
\hline$<3$ months & 1.00 & & & 1.00 & & & 1.00 & & & 1.00 & & \\
\hline 3 to $<6$ months & -2.63 & $-9.30 ; 4.04$ & 0.440 & 1.30 & $-4.28 ; 6.89$ & 0.647 & -4.48 & $-16.06 ; 7.11$ & 0.449 & 0.54 & $-1.27 ; 2.34$ & 0.560 \\
\hline More than 6 months & 6.54 & $2.53 ; 10.55$ & 0.001 & -5.10 & $-8.43 ;-1.76$ & 0.003 & 8.43 & $1.74 ; 15.12$ & 0.014 & -0.68 & $-1.76 ; 0.40$ & 0.215 \\
\hline \multicolumn{13}{|l|}{ Number of comorbidities } \\
\hline None & 1.00 & & & 1.00 & & & 1.00 & & & 1.00 & & \\
\hline 1 & 3.55 & $-1.37 ; 8.47$ & 0.157 & -5.19 & $-9.23 ;-1.16$ & 0.012 & 9.93 & $2.05 ; 17.80$ & 0.013 & -0.86 & $-2.16 ; 0.44$ & 0.195 \\
\hline 2 & 4.49 & $-0.63 ; 9.61$ & 0.086 & -6.46 & $-10.66 ;-2.26$ & 0.003 & 10.11 & $1.88 ; 18.34$ & 0.016 & -1.02 & $-2.37 ; 0.33$ & 0.140 \\
\hline 3 & 5.87 & $-0.04 ; 11.78$ & 0.051 & -7.75 & $-12.62 ;-2.88$ & 0.002 & 15.37 & $5.74 ; 24.99$ & 0.002 & -1.98 & $-3.55 ;-0.41$ & 0.013 \\
\hline $4+$ & 17.18 & $10.14 ; 24.23$ & $<0.001$ & -14.99 & $-20.88 ;-9.11$ & $<0.001$ & 33.06 & $20.77 ; 45.35$ & $<0.001$ & -4.35 & $-6.24 ;-2.46$ & $<0.001$ \\
\hline
\end{tabular}

NHYA

\begin{tabular}{|c|c|c|c|c|c|c|c|c|c|c|c|c|}
\hline I & 1.00 & & & 1.00 & & & 1.00 & & & 1.00 & & \\
\hline ॥ & 16.07 & $9.16 ; 22.98$ & $<0.001$ & -12.61 & $-19.06 ;-6.15$ & $<0.001$ & 22.28 & $10.78 ; 33.77$ & $<0.001$ & -1.86 & $-3.92 ; 0.21$ & 0.078 \\
\hline III & 26.95 & $19.97 ; 33.93$ & $<0.001$ & -18.00 & $-24.49 ;-11.50$ & $<0.001$ & 38.29 & $26.65 ; 49.92$ & $<0.001$ & -3.82 & $-5.90 ;-1.75$ & $<0.001$ \\
\hline IV & 33.28 & $16.44 ; 50.13$ & $<0.001$ & -27.35 & $-41.90 ;-12.81$ & $<0.001$ & 51.63 & $24.63 ; 78.64$ & $<0.001$ & -8.69 & $-13.43 ;-3.95$ & $<0.001$ \\
\hline SMWD (m) & -0.01 & $-0.01 ; 0.00$ & 0.217 & 0.00 & $0.00 ; 0.01$ & 0.313 & -0.01 & $-0.03 ; 0.00$ & 0.109 & 0.00 & $0.00 ; 0.00$ & 0.423 \\
\hline $\mathrm{FEV}_{1} \%$ predicted & -0.55 & $-0.62 ;-0.49$ & $<0.001$ & 0.43 & $0.37 ; 0.49$ & $<0.001$ & -0.80 & $-0.91 ;-0.70$ & $<0.001$ & 0.09 & $0.07 ; 0.11$ & $<0.001$ \\
\hline /C \% predicted & -0.60 & $-0.66 ;-0.53$ & $<0.001$ & 0.46 & $0.39 ; 0.53$ & $<0.001$ & -0.89 & $-1.00 ;-0.78$ & $<0.001$ & 0.11 & $0.09 ; 0.13$ & $<0.001$ \\
\hline $\mathrm{L}_{\text {CO }} \%$ predicted & -0.26 & $-0.31 ;-0.20$ & $<0.001$ & 0.26 & $0.20 ; 0.33$ & $<0.001$ & -0.35 & $-0.44 ;-0.25$ & $<0.001$ & 0.04 & $0.02 ; 0.06$ & $<0.001$ \\
\hline
\end{tabular}

Change in FVC \% predicted between baseline and 1-year follow-up

\begin{tabular}{|c|c|c|c|c|c|c|c|c|c|c|c|c|}
\hline Stable/increase & 1.00 & & & 1.00 & & & 1.00 & & & 1.00 & & \\
\hline $\begin{array}{l}\text { Decrease by } 0 \\
\text { to } 10 \%\end{array}$ & 3.71 & $-0.55 ; 7.97$ & 0.087 & -2.90 & $-6.58 ; 0.77$ & 0.122 & 4.08 & $-3.13 ; 11.29$ & 0.267 & -0.51 & $-1.67 ; 0.65$ & 0.393 \\
\hline Decrease by & 9.08 & $2.48 ; 15.67$ & 0.007 & -8.07 & $-13.81 ;-2.33$ & 0.006 & 11.24 & $0.32 ; 22.16$ & 0.044 & -1.30 & $-3.09 ; 0.50$ & 0.156 \\
\hline
\end{tabular}

Change in $\mathrm{DL}_{\mathrm{CO}} \%$ predicted between baseline and 1-year follow-up

\begin{tabular}{|c|c|c|c|c|c|c|c|c|c|c|c|c|}
\hline Stable/increase & 1.00 & & & 1.00 & & & 1.00 & & & 1.00 & & \\
\hline $\begin{array}{l}\text { Decrease by } 0 \\
\text { to } 10 \%\end{array}$ & 5.46 & $0.85 ; 10.08$ & 0.020 & -0.41 & $-4.43 ; 3.60$ & 0.841 & 10.46 & $2.85 ; 18.07$ & 0.007 & -0.37 & $-1.62 ; 0.88$ & 0.561 \\
\hline $\begin{array}{l}\text { Decrease by } \\
>10 \%\end{array}$ & 7.79 & $0.85 ; 14.73$ & 0.028 & -3.93 & $-9.96 ; 2.10$ & 0.201 & 10.74 & $-0.73 ; 22.21$ & 0.067 & -0.40 & $-2.28 ; 1.47$ & 0.673 \\
\hline hange in FVC \% & ed be & reen baseline & nd last & Illow-up & & & & & & & & \\
\hline Stable/increase & 1.00 & & & 1.00 & & & 1.00 & & & 1.00 & & \\
\hline $\begin{array}{l}\text { Decrease by } 0 \\
\text { to } 10 \%\end{array}$ & 3.44 & $-1.04 ; 7.92$ & 0.133 & -3.30 & $-7.08 ; 0.48$ & 0.087 & 3.18 & $-4.45 ; 10.81$ & 0.414 & -0.22 & $-1.44 ; 0.99$ & 0.719 \\
\hline $\begin{array}{l}\text { Decrease by } \\
>10 \%\end{array}$ & 7.47 & $2.11 ; 12.83$ & 0.006 & -6.50 & $-11.02 ;-1.99$ & 0.005 & 8.80 & $-0.15 ; 17.75$ & 0.054 & -0.87 & $-2.32 ; 0.59$ & 0.242 \\
\hline
\end{tabular}


Table 2 Associations of QoL with clinical parameters at baseline and change in clinical parameters in follow-up (Continued)

\begin{tabular}{|c|c|c|c|c|c|c|c|c|c|c|c|c|}
\hline & \multicolumn{3}{|c|}{$\underline{\mathrm{SGRQ} \text { total }}$} & \multicolumn{3}{|c|}{ EQ 5D VAS } & \multicolumn{4}{|c|}{ UCSD-SOBQ } & \multicolumn{2}{|l|}{ WHO-5 } \\
\hline & beta & $95 \% \mathrm{Cl}$ & $p$-value & beta & $95 \% \mathrm{Cl}$ & $p$-value & beta & $95 \% \mathrm{Cl}$ & $p$-value & beta & $95 \% \mathrm{Cl}$ & $p$-value \\
\hline \multicolumn{13}{|c|}{ Change in $\mathrm{DL}_{\mathrm{CO}} \%$ predicted between baseline and last follow-up } \\
\hline Stable/increase & 1.00 & & & 1.00 & & & 1.00 & & & 1.00 & & \\
\hline $\begin{array}{l}\text { Decrease by } 0 \\
\text { to } 10 \%\end{array}$ & 4.41 & $-0.52 ; 9.35$ & 0.080 & -1.42 & $-5.59 ; 2.75$ & 0.505 & 11.09 & $2.94 ; 19.23$ & 0.008 & -0.44 & $-1.77 ; 0.89$ & 0.518 \\
\hline $\begin{array}{l}\text { Decrease by } \\
>10 \%\end{array}$ & 5.10 & $-0.51 ; 10.72$ & 0.075 & -2.47 & $-7.18 ; 2.25$ & 0.305 & 8.24 & $-0.88 ; 17.36$ & 0.077 & -0.30 & $-1.80 ; 1.21$ & 0.701 \\
\hline GAP index & 3.29 & $1.95 ; 4.64$ & $<0.001$ & -3.41 & $-4.50 ;-2.33$ & $<0.001$ & 6.47 & $4.36 ; 8.58$ & $<0.001$ & -0.50 & $-0.86 ;-0.14$ & 0.007 \\
\hline Stage I & 1.00 & & & 1.00 & & & 1.00 & & & 1.00 & & \\
\hline Stage II & 5.69 & $0.74 ; 10.63$ & 0.024 & -7.04 & $-11.00 ;-3.08$ & $<0.001$ & 16.51 & $8.69 ; 24.34$ & $<0.001$ & -0.92 & $-2.25 ; 0.41$ & 0.177 \\
\hline Stage III & 12.93 & $7.42 ; 18.45$ & $<0.001$ & -13.51 & $-17.96 ;-9.07$ & $<0.001$ & 25.78 & $17.08 ; 34.47$ & $<0.001$ & -1.79 & $-3.27 ;-0.30$ & 0.019 \\
\hline \multicolumn{13}{|c|}{ Overall physician's judgement of clinical course of IPF } \\
\hline Stable disease & 1.00 & & & 1.00 & & & 1.00 & & & 1.00 & & \\
\hline Slow progression & 7.79 & $3.51 ; 12.06$ & $<0.001$ & -3.52 & $-7.14 ; 0.10$ & 0.056 & 11.13 & $4.04 ; 18.21$ & 0.002 & -1.08 & $-2.23 ; 0.08$ & 0.068 \\
\hline Rapid progression & 13.16 & $6.22 ; 20.11$ & $<0.001$ & -9.52 & $-15.39 ;-3.65$ & 0.001 & 19.89 & $8.32 ; 31.47$ & 0.001 & -2.72 & $-4.61 ;-0.83$ & 0.005 \\
\hline $\begin{array}{l}\text { No judgement } \\
\text { possible }\end{array}$ & -0.39 & $-4.93 ; 4.15$ & 0.865 & 1.33 & $-2.43 ; 5.09$ & 0.487 & 1.72 & $-5.72 ; 9.15$ & 0.651 & -0.01 & $-1.23 ; 1.20$ & 0.986 \\
\hline
\end{tabular}

6MWD six-minute walk distance; beta, regression coefficient, $C I$ confidence interval, $D L_{C O}$ diffusing capacity of the lung for carbon monoxide, $E Q-5 D V A S$ EuroQol five-dimensional questionnaire, recorded as a visual analog scale, $F E V$, Forced expiratory volume in $1 \mathrm{~s}, F V C$ forced vital capacity, GAP index Gender, Age, Physiology index, IPF idiopathic pulmonary fibrosis, NYHA New York Heart Association functional class, QoL quality of life, SD standard deviation, SGRQ St. George's Respiratory Questionnaire, USCD-SOBQ University of California San Diego Shortness of Breath Questionnaire, WHO-5 World Health Organization-5 Well-Being Index

stable patients. A similar pattern was seen when comparing patients with a decline of $>10 \%$ in $\mathrm{DL}_{\mathrm{CO}} \%$ predicted with those with stable/improving $\mathrm{DL}_{\mathrm{CO}} \%$ predicted (Fig. 2). Similar associations were also seen for other QoL scores (SQRQ symptom, activity and impact domains, and UCSD-SOBQ, EQ-5D, WHO-5) (Online data supplement; Additional file 2: Table S2).

\section{Association of QoL and mortality}

Over the study period there were 113 deaths (26.7\% of all included patients). Univariate analysis found that change from baseline to last visit in any QoL outcome scores (i.e., SGRQ total score, UCSD-SOBQ, EQ-5D VAS, and WHO-5) were each predictive of mortality (Fig. 3). Patients who died during follow up in this cohort had a significant greater increase in SGRQ total scores from baseline to their last follow-up visit prior to death (mean $11.8 \pm 18.6$ ) compared to surviving patients (mean $4.2 \pm$ 18.9; $\mathrm{HR}=1.03 ; 95 \% \mathrm{CI}: 1.02$ to $1.05 ; p<0.001$ ). Changes from baseline in UCSD-SOBQ scores in patients who died and survivors were $7.0 \pm 29.1$ and $20.4 \pm 1.5$ respectively; $\mathrm{HR}=1.03$; $95 \% \mathrm{CI}: 1.01$ to $1.04 ; p<0.001$. In patients who died, the SGRQ and UCSD-SOBQ scores reported at last follow-up visit were all significantly higher (and EQ-5D VAS, and WHO-5 scores significantly lower) compared to surviving patients (Fig. 3).

After adjusting for change in FVC\% predicted, age, number of comorbid diseases, hospitalisation during follow-up and the physician's global assessment about the disease course, multivariate analysis found that a lower QoL at last available follow-up was significantly associated with mortality (Table 3 ). When evaluating mortality and SGRQ scores at last available follow-up, higher age $(\mathrm{HR}=1.06 ; 95 \% \mathrm{CI}: 1.03$ to $1.09 ; p<0.001)$ and $\mathrm{a}>10 \%$ decline in FVC $\%$ predicted $(\mathrm{HR}=2.34,95 \%$ CI: 1.18 to $4.62 ; p=0.015)$ were each associated with mortality. Furthermore, the higher the number of comorbid diseases the higher the risk for mortality (none versus one: $\mathrm{HR}=2.40,95 \% \mathrm{CI}: 1.15$ to $5.01 ; p=0.02$; none versus two: $\mathrm{HR}=2.10,95 \% \mathrm{CI}: 1.02$ to $4.32 ; p=$ 0.043 ; none versus three: $\mathrm{HR}=2.78,95 \% \mathrm{CI}: 1.26$ to $6.09 ; p=0.011)$. Comparable results were found for the other QoL measures at last follow-up. In contrast, no significant associations between change from baseline to last available follow-up in QoL scores and mortality were observed in multivariate analysis (Table 3).

\section{Association of QoL and hospitalisation and exacerbations}

Over the study period 227 patients were hospitalised for any cause and 31 hospitalised for exacerbations. Univariate and multivariate analysis found that the mean SGRQ and UCSD-SOBQ scores across the follow-up period were all significantly higher (and for univariate analyses EQ-5D VAS, and WHO-5 score significantly lower) in hospitalised patients compared to non-hospitalised patients, with the highest mean SGRQ and UCSD-SOBQ scores throughout follow-up (and lowest EQ-5D VAS and WHO-5 scores) reported in 


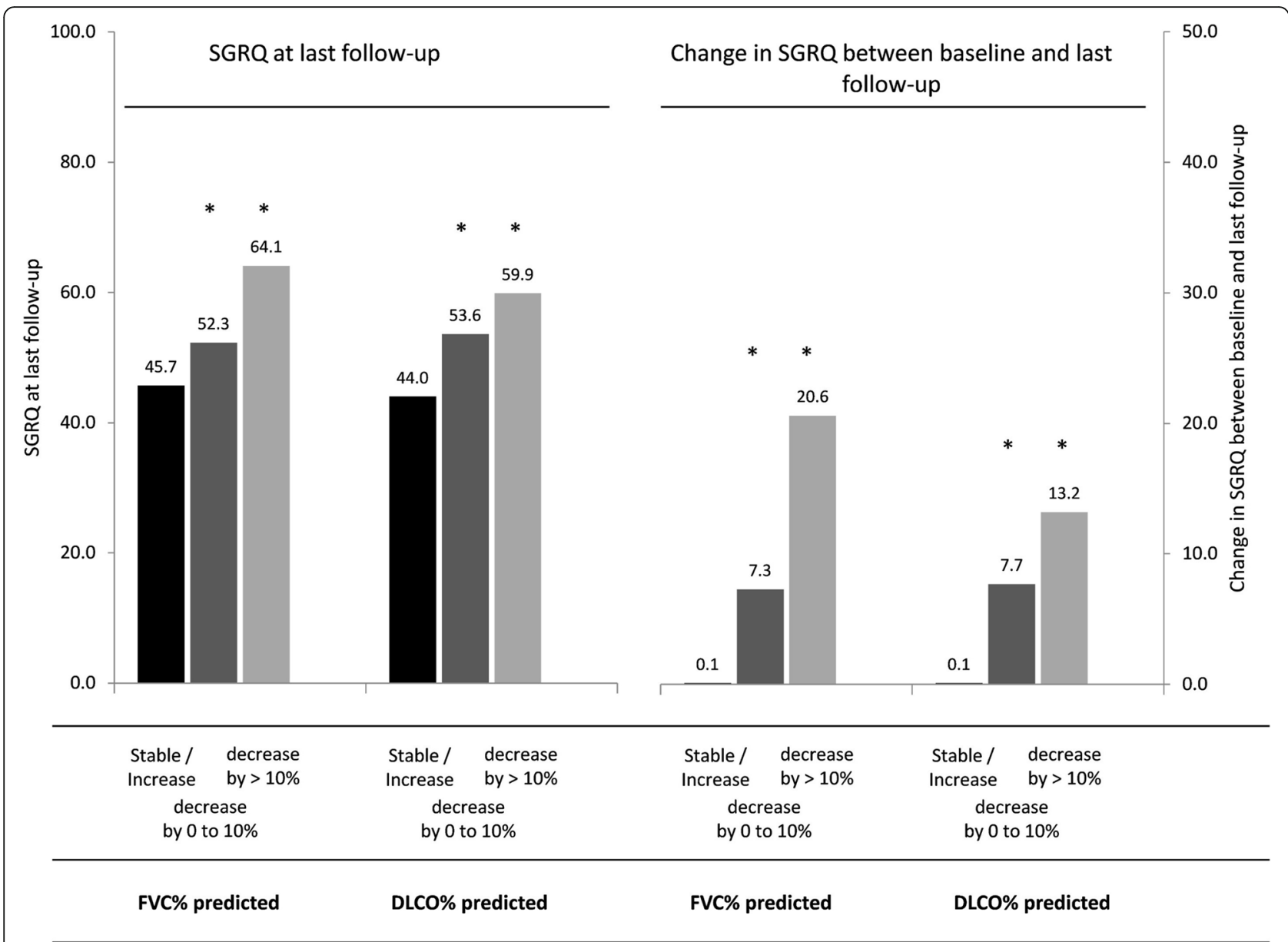

Fig. 2 QoL at last follow-up visit and Change in QoL from baseline to last follow-up visit by change in lung function. ${ }^{*} p$-value $<0.05$ in comparison to category 'stable/ increase' $\mathrm{DL}_{\mathrm{CO}} \%$ predicted: diffusing capacity of the lung for carbon monoxide \% predicted; FVC \% predicted, forced vital capacity \% predicted; QoL, quality of life; SGRQ, St. George's Respiratory Questionnaire

those hospitalised for IPF (Table 4, Fig. 4). Furthermore, across the follow-up period an overall trend was observed, in which successively greater increases in mean SGRQ and UCSD-SOBQ scores and successively greater reductions in EQ-5D VAS and WHO-5 scores were reported by patients hospitalised on 1, 2, 3 and $\geq 4$ separate occasions (Online data supplement; Additional file 3: Figure S1).

Hospitalisation had an adverse impact upon subsequent QoL. Following hospitalisation, significantly higher mean SGRQ scores (total scores and activity and impacts domain scores) and higher mean UCSD-SOBQ scores were reported at the subsequent follow-up visit compared to those reported at the visit prior to hospitalisation (and significantly lower mean EQ-5D VAS and WHO-5 scores) (Online data supplement; Additional file 2: Table S3).

\section{Discussion}

According to the present data, collected from a representative setting of centres with expertise in the management of patients with IPF, a close relationship between QoL and clinical outcomes were found; including clinically meaningful changes in lung function, comorbidities, disease duration and clinical course of IPF (including hospitalisation, acute exacerbations and mortality). For these analyses, we used a range of QoL assessments which, although not originally designed for IPF, have data to support their validity in this patient population, as shown in our previous report and by others $[6,7,9,15-18]$. The optimal tool for QoL assessment in IPF patients remains to be determined, with an adaptation of the SGRQ specifically for use in IPF not yet fully validated or in widespread use [19], while other more focused IPF QoL-measures are also in use or being developed for use (e.g. the Kings' Brief Interstitial Lung Disease health status [K-BILD] and the 'A Tool to Assess Quality of Life in Idiopathic Pulmonary Fibrosis [ATAQ-IPFcA] questionnaires) [9, 20, 21]. It is likely that, while subtle differences may exist, most current tools assess QoL with similar sensitivity and with high or very high correlation between most questionnaires $[7,9]$. 


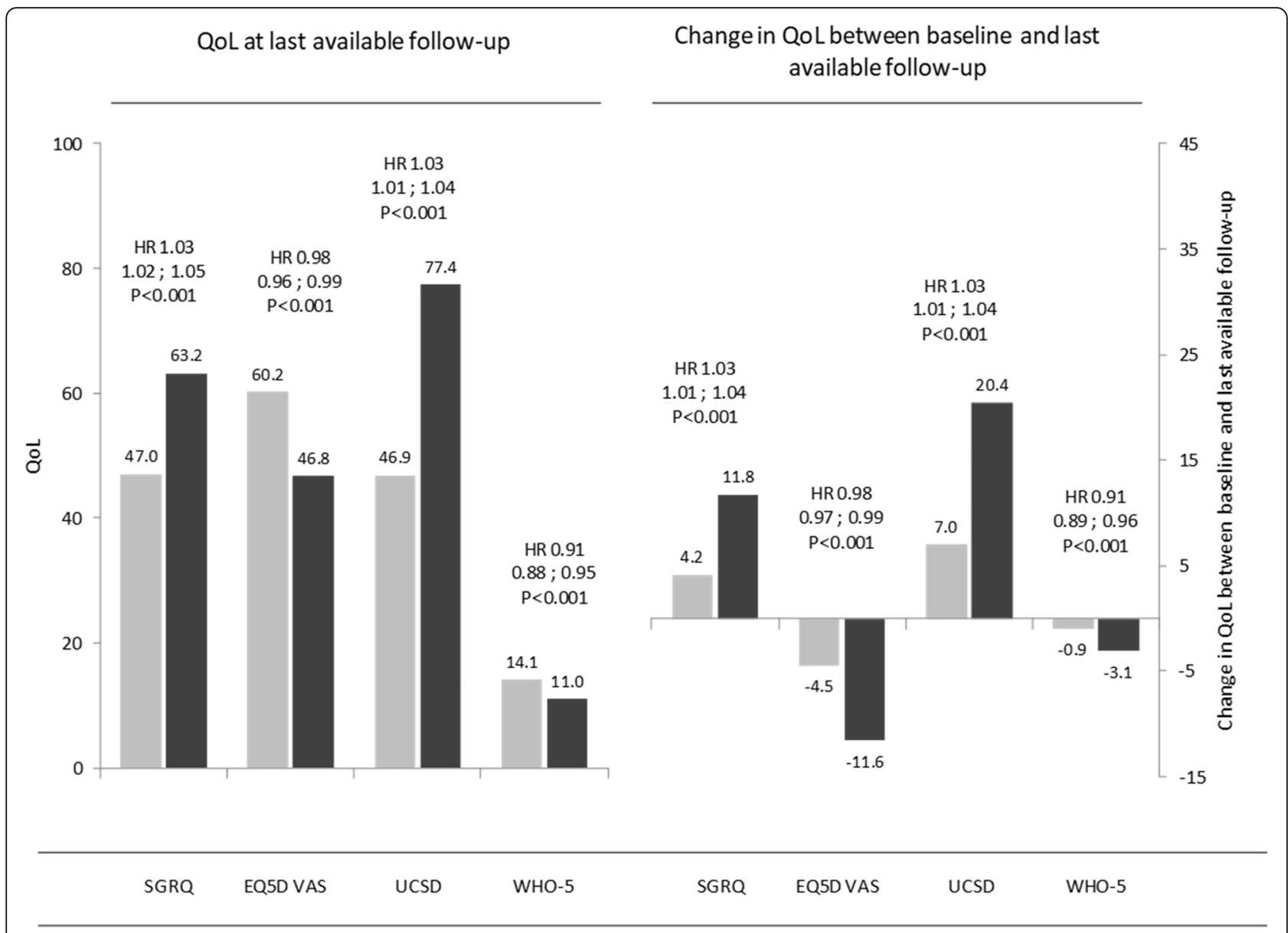

Fig. 3 Association of QoL at last follow-up and change in QoL between baseline and last follow-up with mortality. Light grey and dark grey bares indicate patients who are censored and died during the observation period, respectively. Hazard ratios adjusted for QoL at baseline. EQ-5D VAS, EuroQol five-dimensional questionnaire, recorded as a visual analog scale; HR, Hazard ratio; QoL, quality of life; SGRQ, St. George's Respiratory Questionnaire; USCD-SOBQ, University of California San Diego Shortness of Breath Questionnaire; WHO-5, World Health Organization-5 Well-Being Index

To our knowledge, the only previous report on longitudinal assessments of QoL in IPF patients in clinical practice comes from the Australian IPF registry in a somewhat smaller dataset [6]. In that study, a strong relationship between decline in FVC \% predicted and decline in QoL was shown, with QoL impairment mainly due to dyspnoea (measured using the SGRQ and UCSD-SOBQ scores) although cough and depression (assessed by a VAS scale and the Hospital Anxiety and Depression Scale (HADS)) also contributed [6]. While in that study, no association between baseline QoL measures and mortality was found, a more recent report from the Australian registry indicates that in those patients with mild physiological impairment (FVC $\geq 80 \%$ ), baseline SGRQ and UCSD-SOBQ scores are predictive of mortality, with HRs of 1.11 (95\% CI: 1.06 to 1.15 ) and 1.23 (95\% CI: 1.13 to 1.33$)$ respectively $(p<0.001$ for both) [22]. In contrast to the Australian Registry, we found a significant relationship between lower QoL at last available follow-up but no significant association (on multivariable analysis) between mortality and change in QoL for the total IPF population. Number of comorbidities as well as hospitalisations were driving this QoL decline. Notably, significant changes in both FVC and DLco \% predicted values closely reflected changes in QoL indicating that stabilising lung function may also halt decline of QoL in IPF.

The overall pattern we observed across the cohort was a longitudinal decline in QoL. How then can we seek to improve upon or at least maintain patient QoL in clinical practice? At present, only sparse data on the long-term effects of available therapies on QoL outcomes exist. While disease stabilisation by antifibrotic therapies may offer some potential in maintaining QoL (or retarding decline), available data to support this goal remain limited. In the pivotal phase 3 trials evaluating nintedanib and pirfenidone (each versus placebo), no significant differences in changes in SGRQ scores (from baseline to 52 weeks) were seen between the treatment and placebo arms $[23,24]$ a finding which could be due 
Table 3 Multivariable association of A) QoL at last available follow-up and B) change in QoL between Baseline and last available follow-up and clinical characteristics with mortality

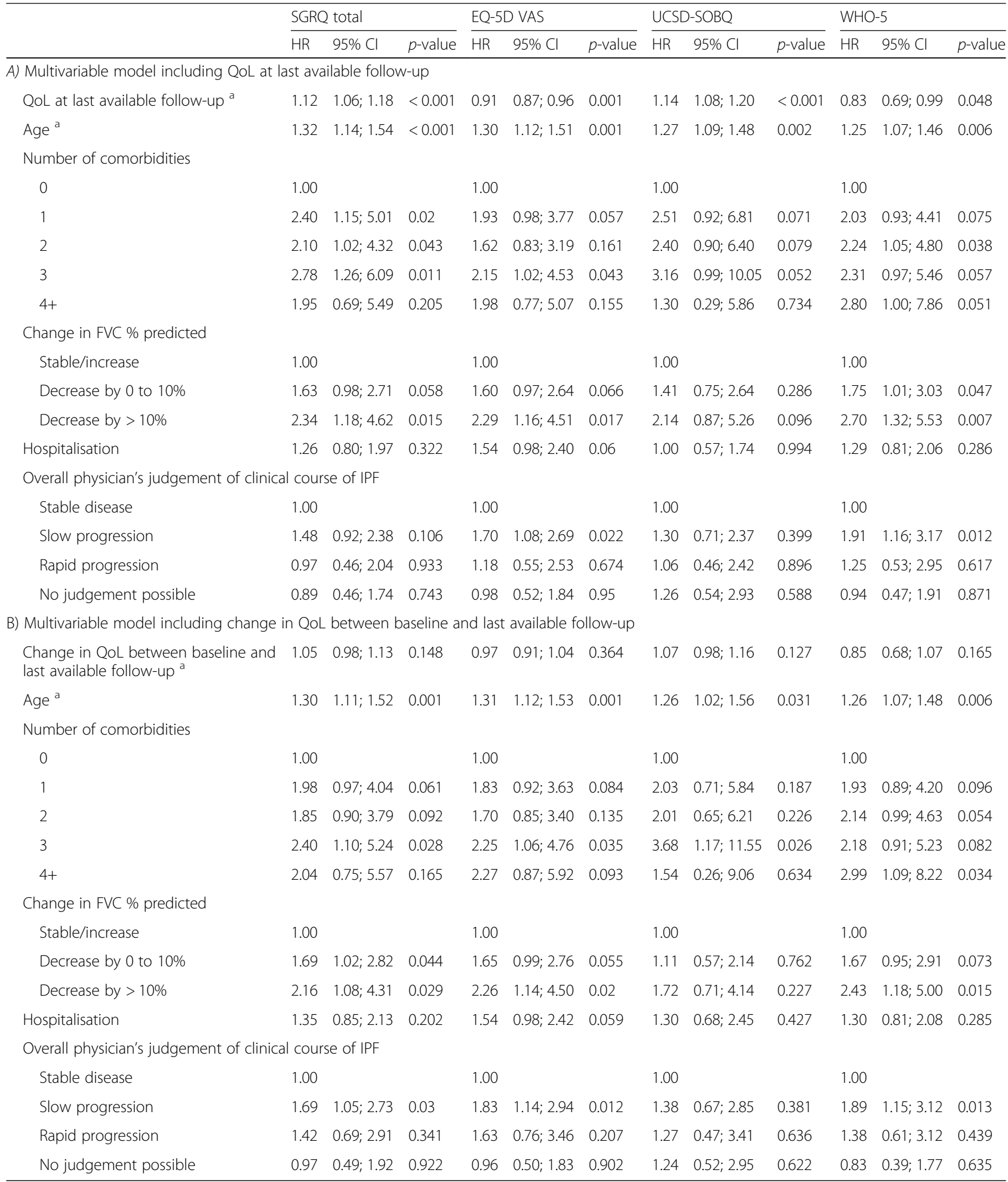

Cl confidence interval, EQ-5D VAS EuroQol five-dimensional questionnaire, recorded as a visual analog scale, $H R$ hazard ratio, FVC forced vital capacity, IPF idiopathic pulmonary fibrosis, QoL quality of life, SD standard deviation, SGRQ St. George's Respiratory Questionnaire, USCD-SOBQ University of California San Diego Shortness of Breath Questionnaire, WHO-5 World Health Organization-5 Well-Being Index

${ }^{\mathrm{a}} \mathrm{HR}$ for increase by 5 points on the QoL scale or by 5 years of age 
Table 4 Multivariable association of QoL and clinical characteristics with any hospitalizations and hospitalizations due to exacerbations in follow-up

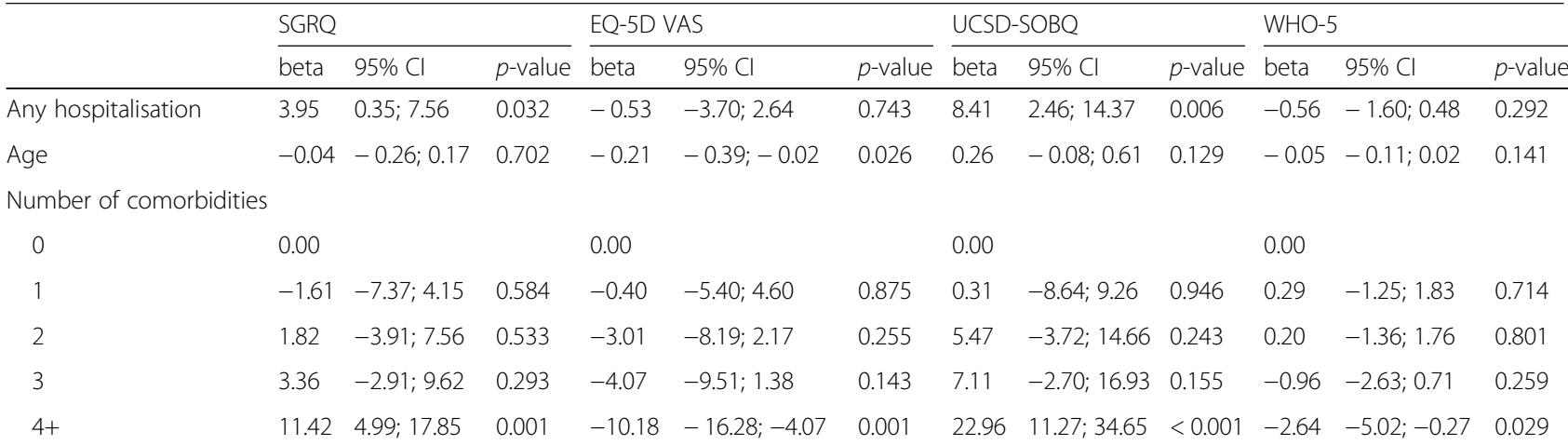

Change in FVC \% predicted

\begin{tabular}{|c|c|c|c|c|c|c|c|c|c|c|c|c|}
\hline Stable/increase & 0.00 & & & 0.00 & & & 0.00 & & & 0.00 & & \\
\hline Decrease by 0 to $10 \%$ & 3.70 & $-0.10 ; 7.51$ & 0.057 & -2.93 & $-6.17 ; 0.32$ & 0.077 & 4.60 & $-1.67 ; 10.87$ & 0.151 & -0.51 & $-1.62 ; 0.61$ & 0.375 \\
\hline Decrease by > 10\% & 8.08 & $2.23 ; 13.93$ & 0.007 & -6.11 & $-11.14 ;-1.08$ & 0.017 & 8.91 & $-0.23 ; 18.05$ & 0.056 & -0.97 & $-2.59 ; 0.66$ & 0.242 \\
\hline \multicolumn{13}{|c|}{ verall physician's judgement of clinical course of IPF } \\
\hline Stable disease & 0.00 & & & 0.00 & & & 0.00 & & & 0.00 & & \\
\hline Slow progression & 7.15 & $4.88 ; 9.42$ & $<0.001$ & -7.24 & $-10.05 ;-4.44$ & $<0.001$ & 10.65 & $5.96 ; 15.35$ & $<0.001$ & -1.62 & $-2.34 ;-0.89$ & $<0.00$ \\
\hline Rapid progression & 22.68 & $16.83 ; 28.52$ & $<0.001$ & -26.37 & $-32.73 ;-20.01$ & $<0.001$ & 33.57 & $24.66 ; 42.48$ & $<0.001$ & -6.35 & $-8.31 ;-4.40$ & $<0.00$ \\
\hline $\begin{array}{l}\text { No judgement } \\
\text { possible }\end{array}$ & 3.02 & $0.33 ; 5.70$ & 0.027 & -2.15 & $-5.16 ; 0.87$ & 0.163 & 1.70 & $-2.96 ; 6.35$ & 0.475 & -1.25 & $-2.11 ;-0.40$ & 0.004 \\
\hline $\begin{array}{l}\text { ospitalisation by } \\
\text { xacerbation }\end{array}$ & 5.35 & $0.64 ; 10.07$ & 0.026 & -1.56 & $-5.78 ; 2.65$ & 0.468 & 10.89 & $2.72 ; 19.05$ & 0.009 & -0.78 & $-2.32 ; 0.76$ & 0.320 \\
\hline ge & 0.04 & $-0.24 ; 0.31$ & 0.791 & -0.37 & $-0.59 ;-0.15$ & 0.001 & 0.40 & $-0.02 ; 0.82$ & 0.062 & -0.04 & $-0.12 ; 0.04$ & 0.383 \\
\hline \multicolumn{13}{|c|}{ umber of comorbidities } \\
\hline 0 & 0.00 & & & 0.00 & & & 0.00 & & & 0.00 & & \\
\hline 1 & -0.33 & $-6.99 ; 6.32$ & 0.922 & -1.35 & $-7.22 ; 4.51$ & 0.651 & 1.41 & $-8.79 ; 11.61$ & 0.786 & 0.23 & $-1.58 ; 2.04$ & 0.804 \\
\hline 2 & 2.93 & $-3.86 ; 9.72$ & 0.397 & -2.43 & $-8.49 ; 3.64$ & 0.433 & 6.77 & $-4.36 ; 17.89$ & 0.233 & -0.09 & $-2.05 ; 1.88$ & 0.930 \\
\hline 3 & 3.52 & $-3.89 ; 10.93$ & 0.352 & -1.79 & $-8.17 ; 4.60$ & 0.583 & 7.09 & $-5.08 ; 19.27$ & 0.253 & -0.94 & $-3.15 ; 1.26$ & 0.403 \\
\hline $4+$ & 13.15 & $5.95 ; 20.36$ & $<0.001$ & -8.90 & $-15.99 ;-1.82$ & 0.014 & 21.07 & $8.29 ; 33.84$ & 0.001 & -2.60 & $-5.56 ; 0.36$ & 0.085 \\
\hline
\end{tabular}

Change in FVC \% predicted

\begin{tabular}{|c|c|c|c|c|c|c|c|c|c|c|c|c|}
\hline Stable/increase & 0.00 & & & 0.00 & & & 0.00 & & & 0.00 & & \\
\hline Decrease by 0 to $10 \%$ & 4.08 & $-0.73 ; 8.88$ & 0.096 & -4.12 & $-8.39 ; 0.15$ & 0.059 & 6.63 & $-1.24 ; 14.50$ & 0.099 & -0.75 & $-2.17 ; 0.67$ & 0.300 \\
\hline Decrease by $>10 \%$ & 7.49 & $0.66 ; 14.32$ & 0.032 & -4.05 & $-10.00 ; 1.90$ & 0.182 & 9.98 & $-0.91 ; 20.86$ & 0.072 & -1.04 & $-2.79 ; 0.72$ & 0.247 \\
\hline \multicolumn{13}{|c|}{ verall physician's judgement of clinical course of IPF } \\
\hline Stable disease & 0.00 & & & 0.00 & & & 0.00 & & & 0.00 & & \\
\hline Slow progression & 6.65 & $3.84 ; 9.46$ & $<0.001$ & -8.90 & $-12.49 ;-5.31$ & $<0.001$ & 9.98 & $3.38 ; 16.58$ & 0.003 & -1.63 & $-2.55 ;-0.70$ & 0.001 \\
\hline Rapid progression & 24.23 & $17.19 ; 31.26$ & $<0.001$ & -27.75 & $-36.15 ;-19.34$ & $<0.001$ & 33.78 & $22.82 ; 44.75$ & $<0.001$ & -6.67 & $-9.06 ;-4.29$ & $<0.001$ \\
\hline $\begin{array}{l}\text { No judgement } \\
\text { possible }\end{array}$ & 2.36 & $-0.77 ; 5.49$ & 0.139 & -1.16 & $-4.97 ; 2.66$ & 0.552 & -0.76 & $-6.46 ; 4.94$ & 0.794 & -0.98 & $-2.00 ; 0.03$ & 0.058 \\
\hline
\end{tabular}

beta regression coefficient, $C I$ confidence interval, EQ-5D VAS EuroQol five-dimensional questionnaire, recorded as a visual analog scale, $F V C$ forced vital capacity, IPF idiopathic pulmonary fibrosis, QoL quality of life, SD standard deviation, SGRQ St. George's Respiratory Questionnaire, USCD-SOBQ University of California San Diego Shortness of Breath Questionnaire, WHO-5 World Health Organization-5 Well-Being Index

to side effects or to short observation times. Furthermore, this has also to be interpreted in light of the here reported differences in associations of QoL to lung functional decline which was statistically significant comparing stable to significantly progressing patients, i.e. with a decrease of FVC $>10 \%$. However, the difference to moderately progressive patients, i.e. a decline between 0 and $10 \%$ was only by trend. In the INPULSIS 


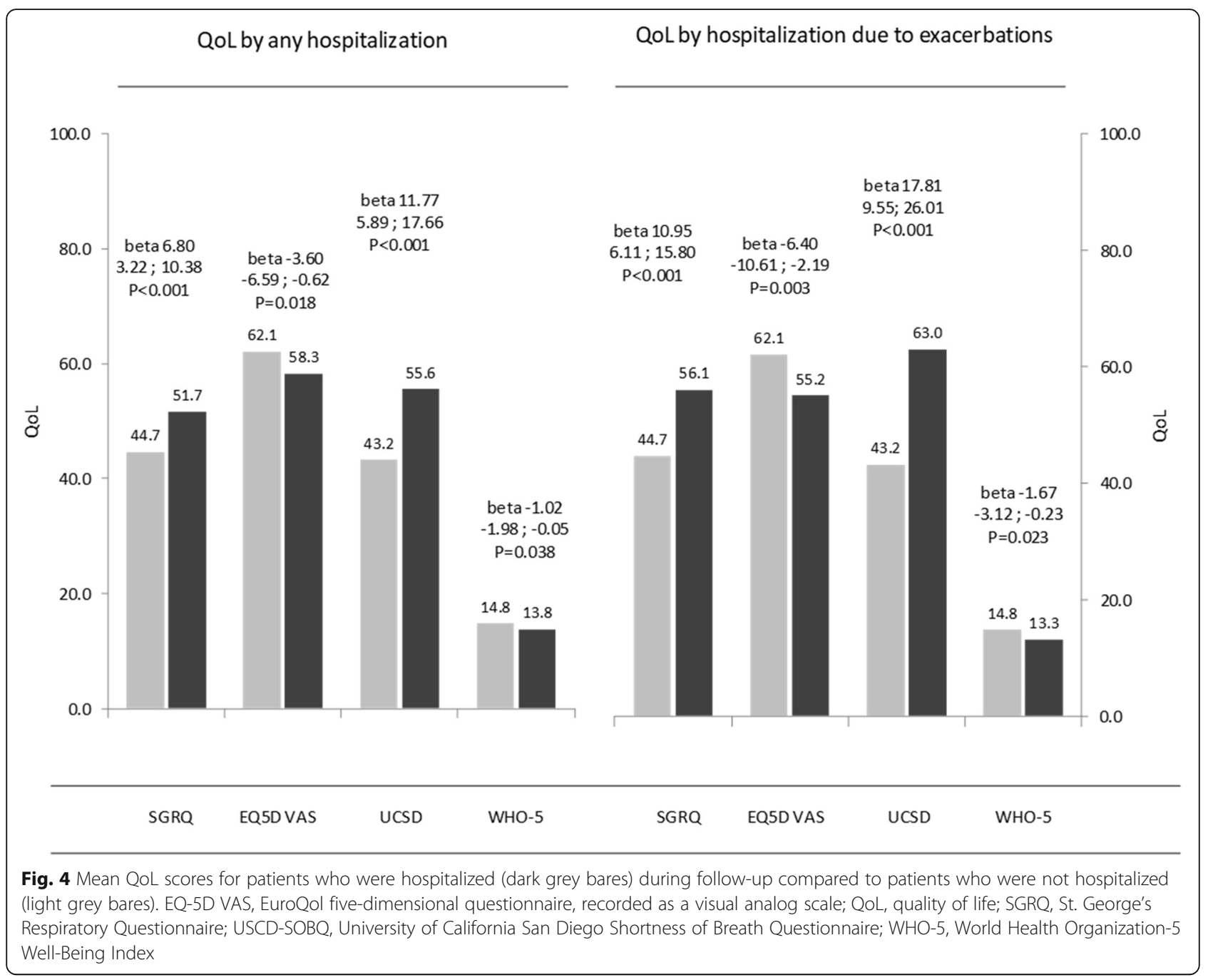

trials for example adjusted absolute mean change from baseline in FVC\% was also within this range with -2.8 for nintedanib and -6.0 for placebo. Still, a subsequent pooled analysis of the TOMORROW and INPULSIS trials comparing nintedanib vs. placebo has shown that the reduction in annual $\mathrm{FVC} \%$ predicted decline seen in the nintedanib arms was accompanied by lower increases in SGRQ compared to placebo (with a mean difference in adjusted mean change from baseline of -2.05 [95\% CI: -3.59 to -0.50 ]; $p<0.0095$ ) [25]. In the step-IPF study, sildenafil was reported to positively impact upon QoL in IPF patients with severe impairment of gas exchange (i.e. DLco $\leq 35 \%$ ) [26]. In a recent randomised controlled trial using nintedanib and sildenafil in combination (INSTAGE study) a positive, while non-significant trend on QoL was observed, but conclusive data is still lacking [27]. On balance, it is likely that optimising pharmacotherapy in IPF patients (and reducing decline in lung function) may also assist in improving QoL in IPF patients. As groups in cohort studies like ours, e.g. with and without antifibrotic therapies, inevitably differ in their clinical characteristics comparisons of therapy effects on QoL in registries may be subject to bias by indication. We therefore refrained from performing comparative analyses with regards to therapy, which however should be assessed in future research.

Non-pharmacotherapy treatments are also important. As physical activity is a strong predictor of IPF disease course, methods to increase physical activity e.g., pulmonary rehabilitation are important in prolonging a more positive life-span, in particular as data suggests that pulmonary rehabilitation may increase QoL [28-30]. Allied to this, greater attention to assessment and treatment of comorbid conditions may improve or at least alleviate longitudinal decline in QoL, although as of yet this remains unproven [4]. For several patients, early palliative care may be an appropriate approach $[5,12]$.

Our study has a number of limitations (above that of using non-IPF specific QoL measures as discussed above). Typically for data collection under clinical practice 
conditions, sites showed considerable variance in terms of number of documented visits and visit time-points, and in terms of completeness of data (each depending on their routine clinical schedule) including QoL reports. Furthermore, a potential bias cannot be excluded, such as underreporting or underdiagnosing of subacute deterioration and any influence of social factors (e.g., family situation) and other aspects external to the disease process. A high number of patients enrolled were excluded from the present analyses due to incomplete data of longitudinal QoL assessment. As some differences had been noted between the group of in- and excluded patients, e.g. a more severe disease and a higher mean number of comorbidities, a bias of our results toward patients with a more severe disease course cannot be excluded. In addition, not every patient completed each of the QoL questionnaires at least yearly as stipulated. However, the relatively large numbers of included patients and completed QoL measures in connection with a long follow-up period do provide a substantially large sample and exposure time from which we found significant differences in a number of outcomes, and association of QoL changes with clinical status. A final limitation is that we have not included potential effects of treatment (including use of anti-fibrotic agents) in the present analyses and cannot report on benefits of such treatment.

\section{Conclusions}

In conclusion, we found strong associations of changes of QoL to important outcomes in IPF; principally decline in lung function, hospitalisation for acute exacerbations and mortality. Pharmacological and non-pharmacological therapies used to reduce these clinically important events should also aim to maintain or even improve QoL as assessed by these equally important patient-reported outcomes.

\section{Additional files}

Additional file 1: Table S4. Sociodemographic and clinical parameters of the study sample comparing patients who were not included due to missing follow-up assessment of QoL in comparison to the cohort included into the analyses. (DOCX $24 \mathrm{~kb}$ )

Additional file 2: Table S1. Quality of life scores at each follow-up visit and change in quality of life over the 3-year follow-up. Table S2. Quality of life scores at last follow-up and change in quality of life between baseline and last follow-up by change in lung function parameters within 1 year after baseline. Table S3. Quality of life scores at visit prior to hospitalisation and subsequent visit after hospitalisation in follow-up. (DOCX $40 \mathrm{~kb}$ )

Additional file 3: Figure S1. Mean difference in QoL scores for patients with one, two, three and more than three hospitalizations compared to patients who were not hospitalized during the follow-up (EQ-5D VAS, EuroQol five-dimensional questionnaire, recorded as a visual analog scale; QoL, quality of life; SGRQ, St. George's Respiratory Questionnaire; USCD-SOBQ, University of California San Diego Shortness of Breath Questionnaire; WHO-5, World Health Organization5 Well-Being Index). (DOCX $110 \mathrm{~kb}$ )

\section{Abbreviations}

6MWD: Six-minute walk distance; $\mathrm{DL}_{\mathrm{co}}$ : Diffusing capacity of the lung for carbon monoxide; EQ-5D VAS: EuroQol five-dimensional questionnaire, recorded as a visual analog scale; FEV : Forced expiratory volume in $1 \mathrm{~s}$; FVC \% predicted: Forced vital capacity \% predicted; GAP index: Gender, Age, Physiology index; NYHA: New York Heart Association functional class; SGRQ: St. George's Respiratory Questionnaire; USCD-SOBQ: University of California San Diego Shortness of Breath Questionnaire; WHO-5: World Health Organization-5 Well-Being Index

\section{Acknowledgements}

The authors would like to thank lain O'Neill for editorial support.

\section{Funding}

This study and all costs associated with the development and publication of this manuscript were funded by Boehringer Ingelheim. The company has no influence on the conduct of the study or interpretation of data, or reporting.

\section{Availability of data and materials}

The datasets used and/or analysed during the current study are available from the corresponding author on reasonable request.

\section{Authors' contributions}

MK, JS, SG, JK, DP and JB analysed and interpreted the data. MK, DP, AP, JK, HuWi and JB are study steering committee members. All authors were involved in collecting the data, in writing the manuscript, and approved the final manuscript.

\section{Ethics approval and consent to participate}

The study materials were approved by the Ethics Committee of the Medical Faculty, Technical University of Dresden (EK 255082012), and by further local ethic committees as per local requirements.

\section{Consent for publication}

Not applicable.

\section{Competing interests}

MK reports grants and personal fees from Roche/InterMune, grants and personal fees from Boehringer Ingelheim, outside the submitted work; AP reports grants and personal fees from Roche/InterMune, grants and personal fees from Boehringer Ingelheim, outside the submitted work; HuWi reports personal fees from Boehringer Ingelheim, and personal fees from Roche, outside the submitted work; MC reports honoraria for lectures from Boehringer Ingelheim Pharma GmbH and Roche Pharma, and for serving on advisory boards from Boehringer Ingelheim, outside the submitted work; DP reports personal fees outside the submitted work from Actelion, Bayer, Boehringer Ingelheim, Sanofi, Biogen, Shield and MSD; DS reports personal fees from Boehringer Ingelheim, Roche, outside the submitted work; SV reports personal fees from Boehringer Ingelheim, personal fees from Roche Pharma, personal fees from Actelion Pharma, grants and personal fees from Novartis Pharma, personal fees from Berlin Chemie, and personal fees from Astra, outside the submitted work; HeWi reports personal fees from Boehringer, personal fees from Roche, during the conduct of the study; personal fees from Bayer, personal fees from Biotest, personal fees from Actelion, personal fees from GSK, and personal fees from Pfizer, outside the submitted work; CN reports honoraria for lectures and serving on advisory boards from Boehringer Ingelheim and Roche Pharma; SA reports case payments from Boehringer Ingelheim, during the conduct of the study; personal fees from Boehringer Ingelheim, and personal fees from Roche, outside the submitted work; SG reports personal fees from Boehringer Ingelheim, personal fees from Roche Pharma, personal fees from Actelion Pharma, grants and personal fees from Novartis Pharma, personal fees from Berlin Chemie, and personal fees from Astra, all outside the submitted work; TW reports grants from Boehringer, during the conduct of the study; TB reports grants from German Center for Lung Research (DZL), personal fees for consultation or lecture from Roche, AstraZeneca, Chiesi, GSK, and Novartis outside the submitted work; JB received grants from Boehringer Ingelheim, and personal fees for consultation or lectures from Actelion, Bayer, Boehringer-Ingelheim, and Roche. He is member of the national and international IPF guideline committee; All other authors declare that they have no competing interests. 


\section{Publisher's Note}

Springer Nature remains neutral with regard to jurisdictional claims in published maps and institutional affiliations.

\section{Author details \\ ${ }^{1}$ Center for interstitial and rare lung diseases, Thoraxklinik, University of Heidelberg, Röntgenstr 1, D-69126 Heidelberg, Germany. ${ }^{2}$ Interstitial Lung Disease Program, National Jewish Health, Denver, CO, USA. ${ }^{3}$ Institut für Klinische Pharmakologie, Medizinische Fakultät, Technische Universität Dresden, Dresden, Germany. ${ }^{4}$ Department Market Access, Boehringer Ingelheim, Ingelheim am Rhein, Germany. ${ }^{5}$ Epidemiologie, Deutsches Rheuma-Forschungsinstitut, Berlin, Germany. ${ }^{6}$ Klinik für Pneumologie, Medizinische Hochschule Hannover, Hannover, Germany. 'Fraunhofer Institute ITEM, Hannover, Germany. ${ }^{8}$ Abteilung für Pneumologie, Department Innere Medizin, Neurologie und Dermatologie, Universitätsklinikum Leipzig AöR, Leipzig, Germany. ${ }^{9}$ Zentrum für Pneumologie und Bereich Pneumologie, Fachkrankenhaus Coswig und Uniklinikum Dresden, Coswig, Germany. ${ }^{10}$ Lungenfachklinik Immenhausen and Universitätsmedizin Göttingen, Kardiologie und Pneumologie, Göttingen, Germany. "'Lungen Clinic Grosshansdorf, Grosshansdorf, Germany. ${ }^{12}$ Klinik für Pneumologie - ELK, Berlin Buch, Berlin, Germany. ${ }^{13}$ Klinik für Innere Medizin V, Pneumologie, Universitätsklinikum Universitätskliniken des Saarlandes, Homburg, Germany. ${ }^{14}$ Krankenhaus Bethanien, Solingen, Germany. ${ }^{15}$ Medizinische Klinik und Poliklinik II, Universitätsklinikum Bonn, Bonn, Germany. ${ }^{16}$ Lungenzentrum München, LZM Bogenhausen-Harlaching, Städtisches Klinikum München $\mathrm{GmbH}$, Munich, Germany. ${ }^{17}$ Center for Internal Medical Studies CIMS, Bamberg, Germany. ${ }^{18}$ Klinik und Poliklinik für Innere Medizin B, Forschungsbereich Pneumologie und Pneumologische Epidemiologie, Universitätsmedizin Greifswald, Greifswald, Germany. ${ }^{19}$ Vivantes Klinikum Spandau, Klinik für Innere Medizin, Berlin, Germany. ${ }^{20}$ Medizinische Klinik und Poliklinik V, Klinikum der LMU, Munich, Germany. ${ }^{21}$ Medizinische Klinik, Klinikum Augsburg, Augsburg, Germany. ${ }^{22}$ Klinikum Würzburg Mitte, Standort Missioklinik, Abteilung Innere Medizin, Pneumologie, Würzburg, Germany. \\ ${ }^{23}$ Asklepios Fachkliniken München-Gauting, Munich, Germany. ${ }^{24}$ Schillerhöhe, Robert Bosch Krankenhaus, Stuttgart, Germany. ${ }^{25}$ Universitätsklinikum Hamburg, Hamburg, Germany. ${ }^{26}$ German Center for Lung Research, gießen, Germany.}

\section{Received: 11 December 2018 Accepted: 27 February 2019} Published online: 15 March 2019

\section{References}

1. Raghu G, Collard HR, Egan JJ, Martinez FJ, Behr J, Brown KK, et al. An official ATS/ERS/JRS/ALAT statement: idiopathic pulmonary fibrosis: evidence-based guidelines for diagnosis and management. Am J Respir Crit Care Med. 2011; 183:788-824.

2. Behr J, Kreuter M, Hoeper MM, Wirtz H, Klotsche J, Koschel D, et al. Management of patients with idiopathic pulmonary fibrosis in clinical practice: the INSIGHTS-IPF registry. Eur Respir J. 2015;46:186-96.

3. Raghu G, Amatto VC, Behr J, Stowasser S. Comorbidities in idiopathic pulmonary fibrosis patients: a systematic literature review. Eur Respir J. 2015; 46:1113-30.

4. Kreuter M, Ehlers-Tenenbaum S, Palmowski K, Bruhwyler J, Oltmanns U, Muley $T$, et al. Impact of comorbidities on mortality in patients with idiopathic pulmonary fibrosis. PLoS One. 2016;11:e0151425.

5. Bajwah S, Ross JR, Peacock JL, Higginson IJ, Wells AU, Patel AS, et al. Interventions to improve symptoms and quality of life of patients with fibrotic interstitial lung disease: a systematic review of the literature. Thorax. 2013;68:867-79.

6. Glaspole IN, Chapman SA, Cooper WA, Ellis SJ, Goh NS, Hopkins PM, et al. Health-related quality of life in idiopathic pulmonary fibrosis: data from the Australian IPF registry. Respirology. 2017;22:950-6.

7. Kreuter M, Swigris J, Pittrow D, Geier S, Klotsche J, Prasse A, et al. Health related quality of life in patients with idiopathic pulmonary fibrosis in clinical practice: insights-IPF registry. Respir Res. 2017;18:139.

8. Yount SE, Beaumont JL, Chen SY, Kaiser K, Wortman K, Van Brunt DL, et al. Health-related quality of life in patients with idiopathic pulmonary fibrosis. Lung. 2016;194:227-34.

9. Szentes BL, Kreuter M, Bahmer T, Birring SS, Claussen M, Waelscher J, et al. Quality of life assessment in interstitial lung diseases:a comparison of the disease-specific K-BILD with the generic EQ-5D-5L. Respir Res. 2018;19:101.
10. Bahmer T, Kirsten AM, Waschki B, Rabe KF, Magnussen H, Kirsten D, et al. Clinical correlates of reduced physical activity in idiopathic pulmonary fibrosis. Respiration. 2016;(91):497-502.

11. Furukawa $T$, Taniguchi $H$, Ando M, Kondoh $Y$, Kataoka K, Nishiyama O, et al. The St. George's respiratory questionnaire as a prognostic factor in IPF. Respir Res. 2017;18:18.

12. Kreuter M, Bendstrup E, Russell AM, Bajwah S, Lindell K, Adir Y, et al. Palliative care in interstitial lung disease: living well. Lancet Respir Med. 2017;5:968-80.

13. Behr J, Hoeper MM, Kreuter M, Klotsche J, Wirtz H, Pittrow D. Characteristics and management of idiopathic pulmonary fibrosis: INSIGHTS-IPF registry. Dtsch Med Wochenschr. 2012;137:2586-8

14. Behr J, Hoeper MM, Kreuter M, Klotsche J, Wirtz H, Pittrow D. Investigating significant health trends in idiopathic pulmonary fibrosis (INSIGHTS-IPF): rationale, aims and design of a nationwide prospective registry. BMJ Open Respir Res. 2014;1:e000010.

15. Swigris JJ, Esser D, Wilson H, Conoscenti CS, Schmidt H, Stansen W, et al. Psychometric properties of the St George's respiratory questionnaire in patients with idiopathic pulmonary fibrosis. Eur Respir J. 2017:49:1601788.

16. Swigris JJ, Wilson H, Esser D, Conoscenti CS, Stansen W, Kline Leidy N, et al. Psychometric properties of the St George's respiratory questionnaire in patients with idiopathic pulmonary fibrosis: insights from the INPULSIS trials. BMJ Open Respir Res. 2018;5:e000278.

17. Swigris JJ, Han M, Vij R, Noth I, Eisenstein EL, Anstrom KJ, et al. The UCSD shortness of breath questionnaire has longitudinal construct validity in idiopathic pulmonary fibrosis. Respir Med. 2012;106:144-55.

18. Swigris JJ, Esser D, Conoscenti CS, Brown KK. The psychometric properties of the St George's respiratory questionnaire (SGRQ) in patients with idiopathic pulmonary fibrosis: a literature review. Health Qual Life Outcomes. 2014;12:124.

19. Yorke J, Jones PW, Swigris JJ. Development and validity testing of an IPFspecific version of the St George's respiratory questionnaire. Thorax. 2010;65: 921-6.

20. Moor CC, Heukels P, Kool M, Wijsenbeek MS. Integrating patient perspectives into personalized medicine in idiopathic pulmonary fibrosis. Front Med (Lausanne). 2017;4:226.

21. Yorke J, Spencer LG, Duck A, Ratcliffe S, Kwong GN, Longshaw MS, et al. Cross-Atlantic modification and validation of the a tool to assess quality of life in idiopathic pulmonary fibrosis (ATAQ-IPF-CA). BMJ Open Respir Res. 2014;1:e000024

22. Jo HE, Glaspole I, Moodley Y, Chapman S, Ellis S, Goh N, et al. Disease progression in idiopathic pulmonary fibrosis with mild physiological impairment: analysis from the Australian IPF registry. BMC Pulm Med. 2018;18:19.

23. Richeldi L, du Bois RM, Raghu G, Azuma A, Brown KK, Costabel U, et al. Efficacy and safety of nintedanib in idiopathic pulmonary fibrosis. N Engl J Med. 2014;370:2071-82.

24. King TE Jr, Bradford WZ, Castro-Bernardini S, Fagan EA, Glaspole I, Glassberg MK, et al. A phase 3 trial of pirfenidone in patients with idiopathic pulmonary fibrosis. N Engl J Med. 2014;370:2083-92.

25. Richeldi L, Cottin V, du Bois RM, Selman M, Kimura T, Bailes Z, et al. Nintedanib in patients with idiopathic pulmonary fibrosis: combined evidence from the TOMORROW and INPULSIS((R)) trials. Respir Med. 2016; 113:74-9.

26. Idiopathic Pulmonary Fibrosis Clinical Research N, Zisman DA, Schwarz M, Anstrom KJ, Collard HR, Flaherty KR, Hunninghake GW. A controlled trial of sildenafil in advanced idiopathic pulmonary fibrosis. N Engl J Med. 2010;363: 620-8.

27. Kolb M, Raghu G, Wells AU, Behr J, Richeldi L, Schinzel B, Quaresma M, Stowasser S, Martinez FJ, INSTAGE Investigators. Nintedanib plus sildenafil in patients with idiopathic pulmonary fibrosis. N Engl J Med. 2018;379:1722-31.

28. Bahmer T, Kirsten AM, Waschki B, Rabe KF, Magnussen H, Kirsten D, et al. Prognosis and longitudinal changes of physical activity in idiopathic pulmonary fibrosis. BMC Pulm Med. 2017;17:104.

29. Tonelli R, Cocconcelli E, Lanini B, Romagnoli I, Florini F, Castaniere I, et al. Effectiveness of pulmonary rehabilitation in patients with interstitial lung disease of different etiology: a multicenter prospective study. BMC Pulm Med. 2017;17:130

30. Gomes-Neto M, Silva CM, Ezequiel D, Conceicao CS, Saquetto M, Machado AS. Impact of pulmonary rehabilitation on exercise tolerance and quality of life in patients with idiopathic pulmonary fibrosis: a SYSTEMATIC REVIEW AND META-ANALYSIS. J Cardiopulm Rehabil Prev. 2018;38:273-8. 